$\frac{S X}{S Y}=$

$\left(r_{S}+r_{R}\right) \cos \overline{180^{\circ}-\theta}+\sqrt{\left(r_{X}+r_{R}\right)^{2}-\left(r_{S}+r_{R}\right)^{2} \sin ^{2} \overline{180^{\circ}-}}=0$

$\left(r_{S}+r_{R}\right) \cos \theta+\sqrt{\left(r_{Y}+r_{R}\right)^{2}-\left(r_{S}+r_{R}\right)^{2} \sin ^{2} \theta}$

is constant.

If $\theta$ is assumed as $90^{\circ}$ at the transition stage, the expression reduces to

$\frac{\left(r_{X}+r_{R}\right)^{2}-\left(r_{S}+r_{R}\right)^{2}}{\left(r_{Y}+r_{R}\right)^{2}-\left(r_{S}+r_{R}\right)^{2}}$ or $\frac{r_{X^{2}}+m r_{X}-n}{r_{Y^{2}}+m r_{Y}-n}$,

where $m=2 r_{R}$ and $n=r_{S}\left(r_{S}-2 r_{R}\right)$.

J. VAUGHAN

C. J. WmKINS

Canterbury University College,

Christchurch,

New Zealand.

May 31.

${ }^{1}$ Wilkins, Brown and Stevens, $J$. Chem. Soc., 163 (1950). 'Dewar, "The Electronic Theory of Organic Chemistry" (Oxford
Univ. Press, 1949).

\section{An Unusual Distribution of the Lanthanons}

AN analysis of the lanthanon (rare earth) fraction from davidite, a uranium-iron-titanium oxide complex from the Radium Hill area of South Australia, has revealed an unusual variation in the abundance of the lanthanons. The accompanying table compares $(a)$ the percentage abundance found for davidite, with $(b)$ that given by Goldschmidt and Thom. assen $^{1}$ for some uranium - titanium-niobium-tantalum complex oxide minerals, and (c) xenotime. Also included in the table are Goldschmidt's values $(d)$ for the average terrestrial abundance of the lanthanons, this abundance differing from that found for monazite mainly in exhibiting a slightly smaller proportion of the lighter (cerium group) lanthanons.

The mineral complex, which has been fully described by Mawson ${ }^{2}$, is substantially primary in nature. The samples used contained approximately two per cent of lanthanon oxides in addition to silica, vanadium, aluminium and other minor components. Fourteen per cent of the total oxalate precipitate consisted of yttria.

Two analyses were carried out with material from different parts of the main ore-body, and almost identical results were obtained. In the first experiment the lanthanons, after complete extraction from the sample, were recovered by oxalate precipitation. In the second experiment, any scandium present, which might otherwise have been reported as yttria, was removed by ether extraction from a thiocyanate solution as recommended by Fischer and Bock ${ }^{3}$. Iron in this second experiment was removed beforehand by ether extraction from a hydrochloric-acid solution.

Where possible, the lanthanons were determined spectrophotometrically, using extinction coefficients previously reported ${ }^{4-6}$. Cerium was determined titrimetrically. A preliminary division into light and heavy groups by controlled double-sulphate fractionation was made. Lanthana and yttria were determined by difference after allowing for gadolinia, terbia and lutetia. The yttria content of the heavy group was checked by average atomic weight determinations.

By showing enrichment towards both ends of the series, the observed distribution lacks any resemblance to the distributions reported by Goldschmidt and Thomassen. If it be accepted that fractionation of the lanthanon ions from a magma proceeds serially, it is difficult to interpret the above distribution unless more than one mineral species is present. Unfortunately, the complex is too fine-grained to permit a test of this hypothesis. The usefulness of the material as a source of lanthanum, erbium and ytterbium is evident.

\section{P. Dixon}

A. W. WYLIE

Division of Industrial Chemistry,

Commonwealth Scientific and Industrial Research Organization,

\section{Melbourne.}

Nov. 22.

${ }^{1}$ Goldschmidt, V. M., and Thomassen, L., Vid. Selsk. Skr., Math. Naturv. Kl., No.'5 (1924).

${ }^{2}$ Mawson, D., Trans. Roy. Soc. South Australia, 68, 334 (1944).

8 Fischer, W., and Bock, B., Z anorg. Chem, 249, 146 (1942).

- Wylie, A. W., J. Soc. Chem. Indust., 69, 143 (1950).

'Moeller, T., and Brantley, J. C., Anal. Chem., 22, 433 (1950).

Spedding, F. H., Fulmer, E. I., Butler, T. A., and Powell, J. E., J. Amer. Chem. Soc., ra, 2349 (1950).

\section{Synthesis of 5-Thiomethylribose}

THeRe has been isolated from yeast ${ }^{1}$, crude oryzanine $^{2}$ and impure cozymase ${ }^{3}$ an unusual nucleoside which on acid hydrolysis yields adenine and a thiomethyl-sugar. Falconer and Gulland claim to have demonstrated that the thiomethylsugar and adenine are combined at the 9-position of the base. The thiomethyl-sugar has been the subject of several investigations; thus Suzuki et al..$^{2,5}$ and Levene and Sobotka ${ }^{6}$ have shown that the thiomethyl group is retained during osazone formation, thereby excluding positions 1 and 2 of the sugar as the sites where it is combined. The thiomethyl-sugar could be readily reduced to a thiomethylpentitol, which on oxidation with lead tetra-acetate yielded $0.9 \mathrm{~mol}$. of formaldehyde ${ }^{7}$, indicating that position 3 in the sugar cannot be the combining position of the thiomethyl group. Satoh and Makino ${ }^{8}$ adduced further evidence which excluded also the $\mathrm{C}_{4}$ of the pentose as the site of the thiomethyl substituent. Previously, Wendt;, using titration data obtained by the Willstätter-Schüdel method, had shown that the thiomethyl-sugar obtained by acidic hydrolysis of the nucleoside was an aldose. Hence all the available evidence indicated that the derivative was a 5-thiomethylpentose.

Raymond ${ }^{\boldsymbol{\theta}}$ synthesized 5-thiomethylxylose and proved that its osazone (that is, 5-thiomethyl-

\begin{tabular}{|c|c|c|c|c|c|c|c|c|c|c|c|c|c|c|}
\hline & La & $\mathrm{Ce}$ & Pr & Nd & $\mathrm{Sm}$ & Lut & Gd† & $\mathrm{Tb} \dagger$ & Dy† & Hot & Er & $\operatorname{Tm} \dagger$ & $\mathrm{Yb}$ & $\mathrm{Lu}$ \\
\hline $\begin{array}{l}a \\
b \\
c \\
d\end{array}$ & $\begin{array}{c}48 \\
0 \cdot 5 \\
0 \\
7\end{array}$ & $\begin{array}{r}29 \\
3 \\
0 \\
31\end{array}$ & $\begin{array}{l}1 \cdot 3 \\
0 \cdot 9 \\
0 \\
5\end{array}$ & $\begin{array}{c}1 \cdot 7 \\
5 \cdot 4 \\
2 \\
18\end{array}$ & $\begin{array}{l}2 \cdot 2 \\
9 \\
4 \\
7\end{array}$ & $\begin{array}{l}0 \cdot 9 \\
0 \\
0 \\
0 \cdot 2\end{array}$ & $\begin{array}{c}1 \cdot 2^{*} \\
12 \\
14 \\
7\end{array}$ & $\begin{array}{l}0 \cdot 6^{*} \\
2 \\
3 \\
1\end{array}$ & $\begin{array}{c}0.9 \\
29 \\
16 \\
7\end{array}$ & $\begin{array}{l}0 \cdot 9 \\
3 \cdot 6 \\
4 \\
1\end{array}$ & $\begin{array}{c}6 \cdot 5 \\
18 \\
25 \\
6\end{array}$ & $\begin{array}{l}0 \cdot 6 \\
2 \\
3 \\
1\end{array}$ & $\begin{array}{l}6 \cdot 1 \\
12 \\
25 \\
7\end{array}$ & $\begin{array}{l}0 \cdot 6^{*} \\
3 \\
5 \\
1 \cdot 5\end{array}$ \\
\hline
\end{tabular}

* Interpolated values. † Maximum values. 